\title{
Estabilidade fenotípica, um complemento relevante na avaliação e classificação de genótipos de algodoeiro para resistência a doenças
}

\author{
Milton Geraldo Fuzatto ${ }^{1}$, Edivaldo Cia ${ }^{1,2}$, Julio Isao Kondo ${ }^{1 .}$
}

\begin{abstract}
${ }^{1}$ Instituto Agronômico, Av. Barão de Itapura, 1481, 13020-902, Campinas-SP; ${ }^{2}$ Bolsista do CNPq. Autor para correspondência: Edivaldo Cia (cia@iac.sp.gov.br)

Data de chegada: 23/04/2012. Aceito para publicação em: 25/04/2013.
\end{abstract}

\section{RESUMO}

Fuzatto, M. G.; Cia, E.; Kondo, J.I. Estabilidade fenotípica, um complemento relevante na avaliação e classificação de genótipos de algodoeiro para resistência a doenças. Summa Phytopathologica, v.39, n.2, p.117-121, 2013.

Neste trabalho é formulado um conceito mais abrangente da resistência a patógenos em genótipos de algodoeiro, mediante inclusão, nos critérios de avaliação, da estabilidade fenotípica desse atributo, quando se consideram ambientes com intensidades diversas de ocorrência das doenças. Para fundamentar o método, um estudo foi realizado com base em dados obtidos em experimentos efetuados, para avaliação de genótipos com respeito à murcha de Fusarium (Fusarium oxysporum $\mathrm{f}$. vasinfectum), mancha-angular (Xanthomonas citri subsp. malvacearum), ramulose (Colletotrichum gossypii var. cephalosporioides), mancha de
Ramularia (Ramularia areola) e aos nematoides Meloidogyne incognita e Rotylenchulus reniformis. Interações genótipos $\mathbf{x}$ ambientes significativas ocorreram em todos esses casos, dando margem a análises subsequentes de estabilidade fenotípica da resistência ou tolerância a esses patógenos. Diferenças notáveis foram observadas quanto a essa característica, e mediante associação dela com um parâmetro expressivo do pior desempenho nas avaliações realizadas, foi possível conferir previsibilidade e classificações mais seguras da reação dos genótipos à incidência das doenças consideradas.

Palavras-chave adicionais: Severidade de doenças, interação genótipos x ambientes.

\section{ABSTRACT}

Fuzatto, M.G.; Cia, E.; Kondo, J.I. Phenotypic stability, a relevant complement in the evaluation and classification of cotton genotypes for disease resistance. Summa Phytopathologica, v.39, n.2, p.117-121, 2013.

In this study, a more comprehensive concept of resistance to pathogens in cotton genotypes is formulated by including, in the evaluation criteria, the phenotypic stability of this attribute, when environments comprising different severity of the disease incidence are considered. To validate the method, a study was carried out based on data obtained in experiments concerning genotype evaluation for Fusarium wilt (Fusarium oxysporum f. vasinfectum), bacterial blight (Xanthomonas citri subsp. malvacearum), "ramulose" or supersprouting (Colletotrichum gossypii var. cephalosporioides), areola mildew (Ramularia areola), and the nematodes Meloidogyne incognita and Rotylenchulus reniformis. Significant genotype $\mathrm{x}$ environment interaction occurred in all these cases, suggesting subsequent analyses on phenotypic stability of the genotype resistance or tolerance to these pathogens. Considerable differences were observed regarding this characteristic and its association with a parameter expressive of the worst performance in the evaluations led to more secure prevision and classification of the reaction of genotypes to the incidence of the considered diseases.

Additional keywords: Disease severity, genotype x environment interaction.

A manifestação de doenças no algodoeiro depende, essencialmente, da patogenicidade do agente causal, do grau de resistência do hospedeiro e das condições ambientais em que ocorre o evento. Este último fator, por envolver circunstâncias que favorecem, ou não, a infecção e o desenvolvimento do patógeno, pode constituir causa de ineficiência na avaliação de genótipos, levando à superestimação de sua resistência e em consequência, à imprevisão de possíveis desempenhos insatisfatórios, como já se verificou, no caso de ramulose (6). Nessas condições, a consideração da interação genótipos x ambientes, em que estes últimos representem situações diferenciadas com respeito à intensidade média de incidência do patógeno, poderia constituir fator decisivo na avaliação e classificação seguras da resistência ou tolerância genética a doenças. Este trabalho teve por objetivo confirmar tais suposições, mediante estudo da estabilidade fenotípica da resistência a diversas doenças, em alguns genótipos de algodoeiro disponíveis no Brasil.

\section{MATERIAL E MÉTODOS}

Para o estudo foram utilizados resultados de testes realizados anualmente pelo Instituto Agronômico (IAC) nos quais são avaliados, para resistência a doenças, cerca de 70 genótipos, dentre cultivares e linhagens avançadas, pertencentes a várias instituições de pesquisa que atuam no Brasil. Tais ensaios foram conduzidos em condições de campo, com quatro repetições e parcelas experimentais constituídas por uma linha com $5 \mathrm{~m}$ de comprimento e 35 plantas como estande inicial. Na avaliação foram atribuídas, no nível de plantas ou de parcelas, 
conforme a doença, notas de 1 a 5 , crescentes com a intensidade de ocorrência dos sintomas. Em tais condições, os genótipos foram avaliados para murcha de Fusarium (Fusarium oxysporum f: vasinfectum), mancha-angular (Xanthomonas citri subsp. malvacearum), ramulose (Colletotrichum gossypii var. cephalosporioides), mancha de Ramularia (Ramularia areola) e para os nematoides Meloidogyne incognita e Rotylenchulus reniformis. Com exceção da ramulose e mancha-angular, casos em que foram feitas inoculações, as demais doenças e nematoides ocorreram naturalmente.

No presente estudo foram utilizados genótipos que haviam sido avaliados, para cada doença, em, pelo menos, quatro ambientes, caracterizados por anos agrícolas, localidades, ou combinação desses fatores. Nessas condições, foram utilizados dados dos seguintes anos e localidades:2006/07, 2007/08, 2008/09 e 2009/10, para murcha de Fusarium (Caiabu), nematoide Rotylenchulus (Leme), nematoide Meloidogyne (Adamantina), mancha de Ramularia (Pindorama, Ituverava e Senador Canedo), ramulose (Piracicaba) e mancha-angular (Campinas). Em cada caso, foi realizado, para a variável nota, uma análise conjunta de variância e, verificada a ocorrência de interação genótipos x ambientes significativa, procedeu-se, então, a estudos de estabilidade fenotípica e caracterização da reação à respectiva doença, em cada genótipo. Para tanto, foram realizadas análises de regressão linear entre as notas médias atribuídas aos genótipos em cada ano e os índices ambientais codificados, conforme proposto por Eberhart \& Russel (4). Calculados os coeficientes de regressão, verificou-se, então, se eles diferiam significativamente do valor 0 (zero), pelo teste " $\mathrm{t}$ " a $5 \%$, tendo sido este o critério estabelecido para definir a estabilidade ou não $(b \neq 0)$, do genótipo considerado. Complementarmente, esta característica foi verificada, também, mediante o teste "F", pelo efeito de ambientes dentro de genótipos. Como se vê, o critério adotado difere dos que são usualmente utilizados em estudos de estabilidade e adaptabilidade $(1,3,4,5$,$) aproximando-se todavia,$ do conceito formulado por Tai (7), para definir como ideal, o genótipo de desempenho eficiente e invariável segundo o ambiente. Para complementar a caracterização da resistência ou tolerância, levou-se em conta, ainda, a maior nota média, dentre os vários ambientes, atribuída ao genótipo considerado, representativa, portanto, do seu potencial de reação à doença em questão. Para enquadrar, segundo esse parâmetro, os genótipos em termos conceituais, utilizou-se escala adaptada de Cia et al. (2), a saber: nota menor do que 1,5 , altamente resistente; de 1,5 a 2 , resistente; de 2,1 a 2,5, moderadamente resistente, de 2,6 a 3,2, moderadamente suscetível; de 3,3 a 4,3, suscetível; maior do que 4,3, altamente suscetível. A combinação dessas características - estabilidade/ instabilidade, de um lado, e as notas máximas referidas, de outro permitiu o estabelecimento de 12 classes de enquadramento dos genótipos, segundo a perspectiva de seu desempenho em face das doenças consideradas.

\section{RESULTADOS E DISCUSSÃO}

Confirmando os pressupostos do trabalho, o efeito de ambientes e a interação genótipos $\mathrm{x}$ ambientes foram significativos para todas as doenças estudadas, com valores " $F$ " de, respectivamente, 9,43** e 3,10** para ramulose; $7,66^{* *}$ e 3,26** para murcha de Fusarium; $4,48 * *$ e $2,29 *$ para Rotylenchulus; $55,46 * *$ e $3,33 * *$ para Ramularia; $2,50 *$ e $2,13 *$ para mancha-angular; e $7,52 * *$ e $1,52 *$ para Meloidogyne. Foram também significativos os efeitos de genótipos, para todas as doenças estudadas, cujos desempenhos, expressos pelas notas médias, foram os seguintes: a) murcha de Fusarium: Fibermax 993 (3,60), Fibermax $966(3,35)$, IPR Jataí (2,03), Deltaopal (2,93), IAC 25 RMD $(1,62)$ e IAC 20-233 (1,78); b) mancha de Ramularia: Fibermax $993(3,44)$, FMT $701(2,66)$, IPR Jataí $(3,15)$, IAC 25 RMD $(2,58)$, Nuopal $(3,38)$ e Fibermax $966(1,66)$; c) nematoide Meloidogyne: Fibermax 966 (3,54), IPR Jataí $(1,66)$, BRS Buriti $(2,77)$, IAC 25 RMD $(1,56)$, Deltaopal $(2,66)$ e IAC 20-233 (1,37); d) nematoide Rotylenchulus: Fibermax 993 (2,49), IPR Jataí (2,32), BRS Buriti $(2,74)$, IAC 25 RMD $(2,24)$, Deltaopal $(2,98)$, Fibermax $966(3,81)$ e IAC 20-233 $(1,84)$; e) ramulose: Fibermax $966(2,91)$, IPR Jataí $(3,91)$, Fibermax 993 $(3,29)$, Deltaopal $(2,96)$, IAC 25 RMD $(2,33)$, IAC 02-2226 $(1,68)$ e Nu-15 (4,37); f) mancha-angular: Fibermax 993 (1,02), IPR Jataí $(2,10)$, BRS Buriti $(1,45)$ e Deltaopal $(1,04)$. A interação genótipos $\mathrm{x}$ ambientes justificou as análises de regressão e estudos de estabilidade fenotípica subsequentes, cujos resultados, para genótipos de desempenhos típicos, se encontram nas Tabelas 1 e 2, e na Figura 1.

Segundo o critério adotado, o genótipo ideal teria coeficiente de regressão igual a 0 (zero) e maior nota média igual ou próxima a 1 (um), o que o classificaria como estável e altamente resistente (E-AR). São exemplos dessa classe os genótipos FIBERMAX 993 e DELTAOPAL, no caso de mancha-angular (Tabela 2). No extremo oposto encontra-se, na mesma Tabela, o genótipo $\mathrm{Nu}-15$, no caso de ramulose, estável e altamente suscetível (E - AS). Entre esses extremos, e igualmente estáveis, encontram-se genótipos com desempenhos satisfatórios, como IAC 25 RMD no caso de Fusarium e IAC 20-233 no de Meloidogyne, (Tabela 1), IAC $02-$ 2226 no de ramulose e FIBERMAX 966 no de Ramularia (Tabela 2); outros com desempenhos intermediários, como DELTAOPAL para Meloidogyne e BRS BURITI para Rotylenchulus (ambos na Tabela 1); e ainda outros com desempenhos inadequados como FIBERMAX 966, com respeito a Rotylenchulus (Tabela 1) e IPR JATAÍ quanto à ramulose (Tabela 2). A despeito de suas diferenças, no que se refere ao grau de resistência às doenças, tais genótipos apresentam, em comum, a previsibilidade do seu desempenho, isto é, sejam positivos ou negativos os resultados, as avaliações realizadas podem ser consideradas seguras e sem ambiguidades.

Dentre os genótipos que se mostraram instáveis, alguns revelaram desempenhos aceitáveis, como IAC 20 - 233 para Rotylenchulus (Tabela 1) e BRS BURITI para mancha-angular (Tabela 2). Tal como no grupo dos estáveis, tais genótipos não levam a grandes equívocos na sua avaliação, porquanto, as diferenças entre as notas que obtiveram nos vários ambientes não chegam a promover mudanças substanciais nas classes de resistência em que podem ser enquadrados. Mudanças dessa ordem, entretanto, verificaram-se em diversos casos neste trabalho, dos quais os mais expressivos ocorreram com os genótipos FMT 701 e FIBERMAX 993 para Fusarium (Tabela 1); FIBERMAX 993 para Rotylenchulus e FIBERMAX 966 para Meloidogyne (Tabela 1) e para ramulose (Tabela 2); e IPR JATAÍ e NUOPAL para Ramularia (Tabela 2). Em todos esses casos, dependendo do ambiente em que fossem avaliados, os mencionados genótipos poderiam ter sua resistência às respectivas doenças superestimada, ou, ao contrário, sua suscetibilidade minimizada. $\mathrm{O}$ critério exposto neste trabalho pode evitar tais equívocos, na medida em que aumenta a previsibilidade de desempenho e estabelece classificação mais segura dos genótipos, quanto à reação a doenças. 
Tabela 1. Notas médias atribuídas a genótipos de algodoeiro em avaliações sob intensidades diversas de ocorrência de doenças, e parâmetros de estabilidade fenotípica da resistência ou tolerância aos patógenos.

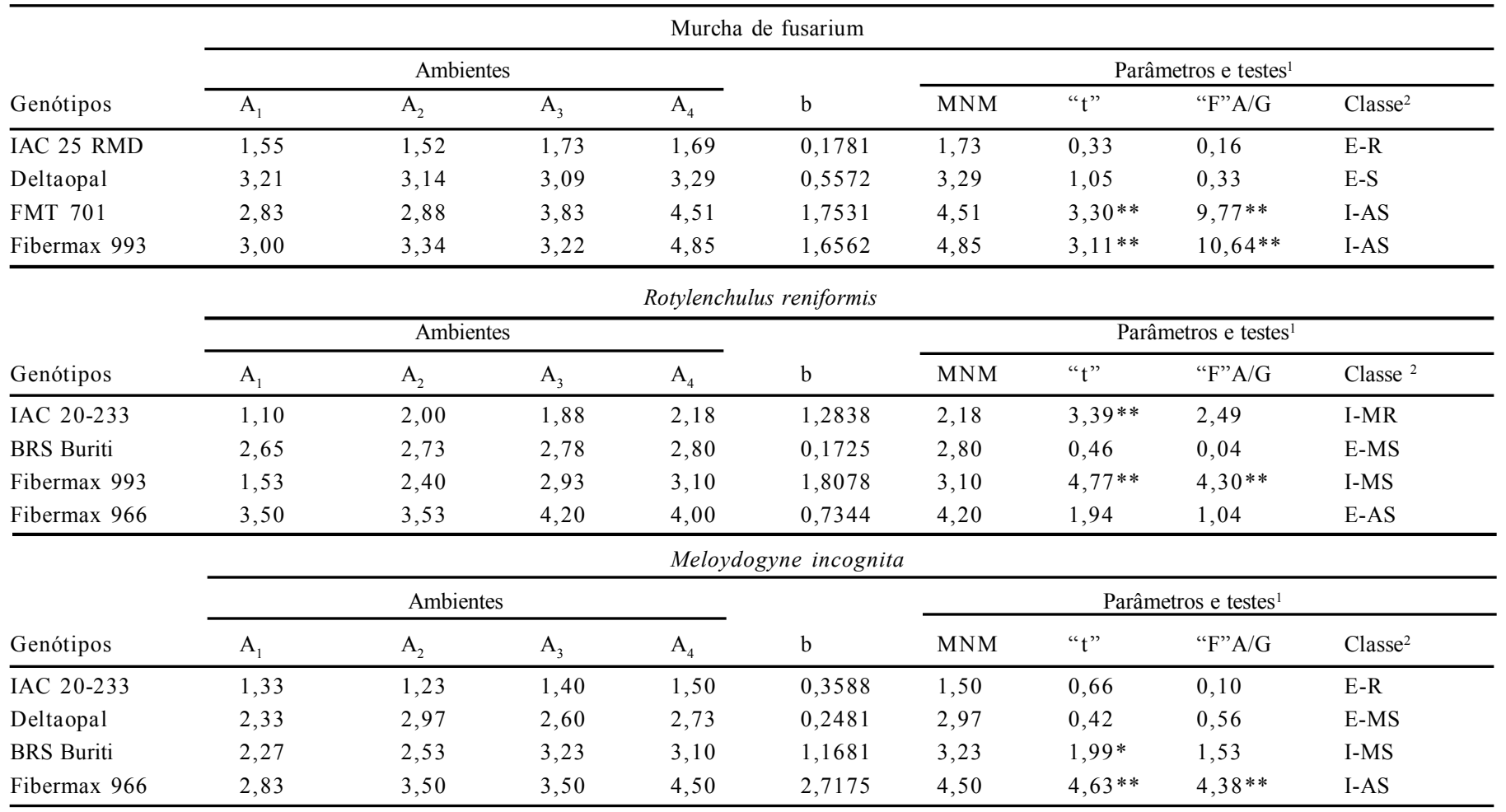

'b = Coeficiente de regressão linear; MNM = Maior nota média nas avaliações; " $t$ " Teste para $b \neq 0$; " $F$ " $A / G=$ Teste do efeito de ambiente dentro de genótipo. ${ }^{2}$ Caracterização da resistência (combinação de estabilidade e potencial de reação à incidência da doença): $\mathrm{E}=\mathrm{estável;} \mathrm{I}=$ instável; $\mathrm{AR}=\mathrm{altamente}$ resistente; $\mathrm{R}=$ resistente; $\mathrm{MR}=$ medianamente resistente; $\mathrm{MS}=$ medianamente suscetível; $\mathrm{S}=$ suscetível e AS = altamente suscetível.

Tabela 2. Notas médias atribuídas a genótipos de algodoeiro em avaliações sob intensidades diversas de ocorrência de doenças, e parâmetros de estabilidade fenotípica da resistência ou tolerância aos patógenos.

\begin{tabular}{|c|c|c|c|c|c|c|c|c|c|}
\hline \multirow[b]{3}{*}{ Genótipos } & \multicolumn{9}{|c|}{ Mancha-angular } \\
\hline & \multicolumn{4}{|c|}{ Ambientes } & \multirow[b]{2}{*}{$\mathrm{b}$} & \multicolumn{4}{|c|}{ Parâmetros e testes ${ }^{1}$} \\
\hline & $\mathrm{A}_{1}$ & $\mathrm{~A}_{2}$ & $\mathrm{~A}_{3}$ & $\mathrm{~A}_{4}$ & & MNM & "t" & "F"A/G & Classe $^{2}$ \\
\hline Deltaopal & 1,01 & 1,00 & 1,02 & 1,00 & 0,0990 & 1,02 & 0,52 & 0,23 & E-AR \\
\hline BRS Buriti & 1,31 & 1,18 & 1,41 & 1,88 & 1,3384 & 1,88 & $6,98 * *$ & $2,70 *$ & $\mathrm{I}-\mathrm{R}$ \\
\hline IPR Jataí & 1,56 & 1,79 & 2,13 & 2,80 & 2,6820 & 2,80 & $13,99 * *$ & $8,72 * *$ & I-MS \\
\hline & \multicolumn{4}{|c|}{ Ambientes } & & \multicolumn{4}{|c|}{ Parâmetros e testes ${ }^{1}$} \\
\hline Genótipos & $\mathrm{A}_{1}$ & $\mathrm{~A}_{2}$ & $\mathrm{~A}_{3}$ & $\mathrm{~A}_{4}$ & $\mathrm{~b}$ & MNM & "t" & "F"A/G & Classe $^{2}$ \\
\hline IAC $02-2226$ & 1,73 & 1,50 & 1,60 & 1,89 & 0,4338 & 1,89 & 0,82 & 1,03 & E-R \\
\hline Fibermax 966 & 2,07 & 2,99 & 3,12 & 3,49 & 1,5020 & 3,49 & $2,85^{*}$ & $13,09 * *$ & I-S \\
\hline IPR Jataí & 3,82 & 4,00 & 3,87 & 4,26 & 0,6322 & 4,26 & 1,19 & 2,05 & E-S \\
\hline Genótipos & $\mathrm{A}_{1}$ & $\mathrm{~A}_{2}$ & $\mathrm{~A}_{3}$ & $\mathrm{~A}_{4}$ & $\mathrm{~b}$ & MNM & "t" & “F”A/G & Classe $^{2}$ \\
\hline Fibermax 966 & 1,32 & 1,74 & 1,32 & 1,96 & 0,3472 & 1,96 & 1,70 & 2,22 & E-R \\
\hline IAC 25 RMD & 1,84 & 2,66 & 2,42 & 2,74 & 0,6455 & 2,74 & $3,17 * *$ & $5,69 * *$ & I-MS \\
\hline IPR Jataí & 2,14 & 2,48 & 3,52 & 3,66 & 1,1757 & 3,66 & $5,77 * *$ & $13,62 * *$ & I-S \\
\hline Nuopal & 2,94 & 3,26 & 4,14 & 4,50 & 1,4644 & 4,50 & $7,18 * *$ & $20,69 * *$ & I-AS \\
\hline
\end{tabular}

'b = Coeficiente de regressão linear; MNM = Maior nota média nas avaliações; " $t$ " Teste para $b \neq 0$; "F" A/G = Teste do efeito de ambiente dentro de genótipo. ${ }^{2}$ Caracterização da resistência (combinação de estabilidade e potencial de reação à incidência da doença): $\mathrm{E}=\mathrm{estável;} \mathrm{I}=$ instável; $\mathrm{AR}=\mathrm{altamente}$ resistente; $\mathrm{R}=$ resistente; $\mathrm{MR}=$ medianamente resistente; $\mathrm{MS}=$ medianamente suscetível; $\mathrm{S}=$ suscetível e AS = altamente suscetível. 

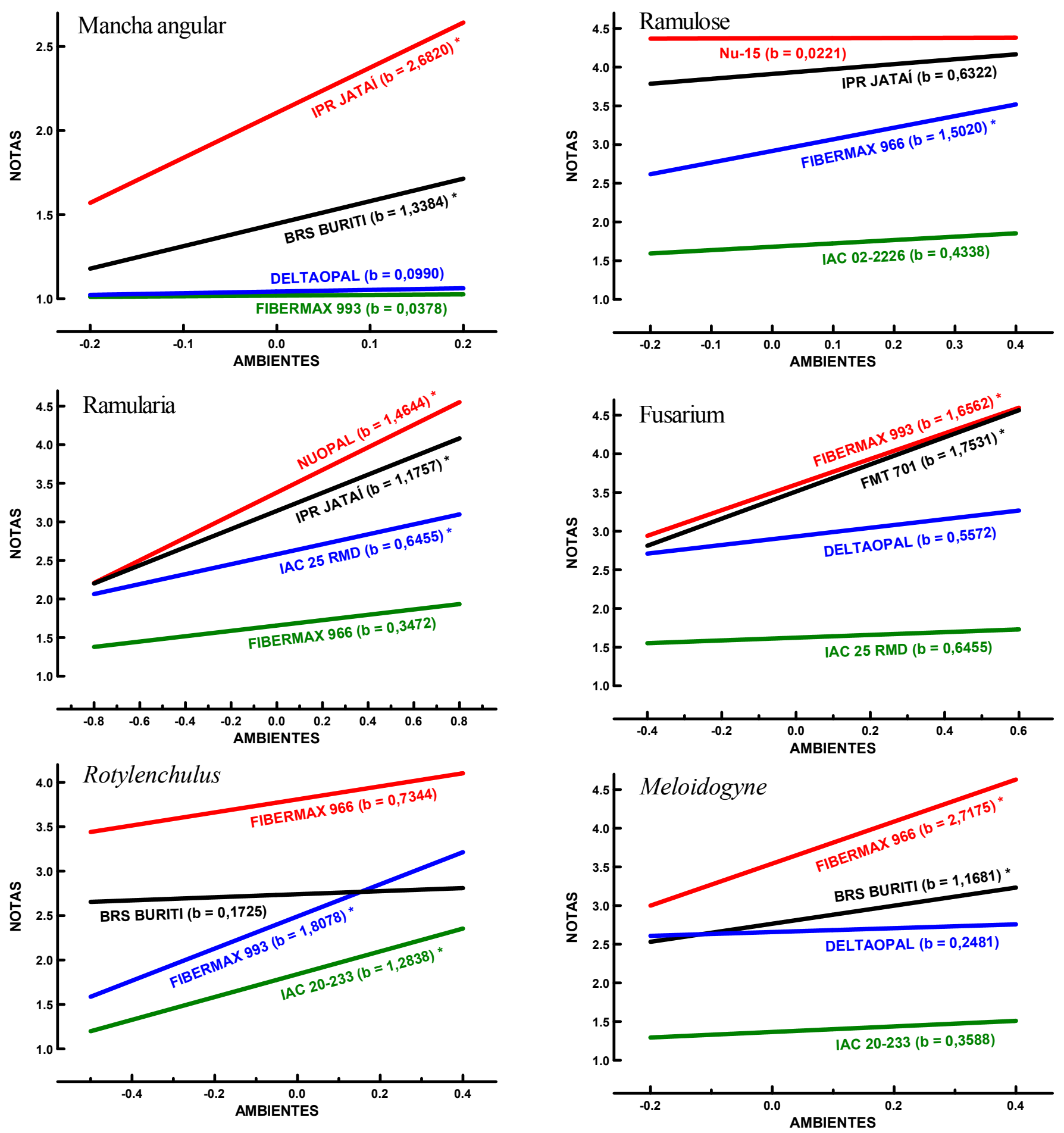

Figura 1. Linhas de regressão representativas da estabilidade fenotípica da resistência a doenças, em genótipos de algodoeiro.

\section{AGRADECIMENTOS}

Trabalho realizado com apoio da FAPESP, do CNPq, do IMA e do FIALGO.

\section{REFERÊNCIAS BIBLIOGRÁFICAS}

1. Bilbro, J.D.; Ray, L. L. Environmental stability and adaptation of several cotton cultivars. Crop. Science, Madison, v.16, p. 821$824,1976$.
2. Cia, E.; Fuzatto, M.G.; Lüders, R.R.; Kondo, J.I; Galbieri, R.; Almeida, W.P.; Oliveira, A.B.; Lebedenco, A.; Pereira, A.T.; Martins, A.L.M.; Campos, D.J.T.; Mesquita, D.; Bolonhezi, D.; Foltran, D. E.; Chiavegato, E.J.; Moresco, E.; Furlani Jr, E.; Takizawa, E.K.; Melo, F.L.A.; Dojas, F.; Farias, F.J.C.; Kasai, F.S.; Cunha, E.F.; Belot, J.L.; Silva, J.C.; Carvalho, L.H.; Beriam, L.O.S.; Lanza, M.A.; Ito, M.A.; Pereira, M.; Michelotto, M.D.; Ito, M.F.; Pedrosa, M.B.; Ruano, O.; Pupim Junior, O.; Gallo, P.B.; Reco, P.C.; Aguiar, P.H.; Rossetto, R.; Freitas, R.S.; Muramoto, S.P. Desempenho de cultivares e linhagens de algodoeiro em face da ocorrência de doenças e nematoides. Boletim Científico do Ins- 
tituto Mato-Grossense do Algodão, Cuiabá,, no. 1, p. 1-38, 2008.

3. Cruz, C.D.; Torres, R.A.; Vencovsky, R. An alternative approach to the stability analysis proposed by Silva and Barreto. Revista Brasileira de Genética, Ribeirão Preto, v. 12: p. 567-580, 1989.

4. Eberhart, S.A.; Russel, W.A. Stability parameters for comparing varieties. Crop Science. Madison, v.6, p. 36-40. 1966.

5. Finlay, K.W.; Wilkinson, G.N. The analysis of adaptation in a plant-breeding programme. Australian Journal of Agricultural
Research, East Melbourne, v. 14, p. 742-754. 1963.

6. Fuzatto, M.G.; Cia, E.; Lüders, R.R.; Galbieri, R.; Kondo, J.I. Estabilidade fenotípica como critério de avaliação de genótipos de algodoeiro para resistência à ramulose. In: Congresso Brasileiro de Algodão, 7., 2009. Foz do Iguaçu. Anais... Campina Grande: EMBRAPA/Algodão, p. 1675-1679,2009. 1 CD ROM.

7. Tai, G.C.C. Genotypic stability analysis and its application to potato regional trials. Crop. Science., Madison, v. 11, p. 184-190, 1971. 